\title{
Compliance of state registered nurses to nursing standards during practice in tertiary facilities in Malawi
}

\author{
Edoly Shirley Lengu ${ }^{1}$, Rodwell Gundo ${ }^{1}$, Alfred Maluwa ${ }^{2 *}$, Noel Mbirimtengerenji ${ }^{1}$ \\ ${ }^{1}$ Department of Medical-Surgical Nursing, Kamuzu College of Nursing, University of Malawi, Lilongwe, Malawi \\ ${ }^{2}$ Research Directorate, Kamuzu College of Nursing, University of Malawi, Lilongwe, Malawi \\ Email: ${ }^{*}$ aomaluwa@kcn.unima.mw
}

Received 10 May 2013; revised 12 June 2013; accepted 15 July 2013

Copyright (c) 2013 Edoly Shirley Lengu et al. This is an open access article distributed under the Creative Commons Attribution License, which permits unrestricted use, distribution, and reproduction in any medium, provided the original work is properly cited.

\begin{abstract}
The aim of this study was to describe the quality of practice offered by nurses to patients who underwent surgical incision into the abdomen (post-laparotomy) at tertiary hospitals (Kamuzu, Mzuzu, Queen Elizabeth and Zomba) in Malawi. The study design was descriptively cross sectional and utilized a quantitative data collection and analysis method. All available 48 registered nurses in the surgical ward of four central hospitals and 100 patients that were admitted in the ward during the time of study were recruited. A 3-point scale rating consisting of compliance $(C=1)$, partial compliance $(C<1.0-0.5)$ and non compliance $(C<0.5-0.0)$ was used to describe the nurse midwives compliance with the process standards of care. Results show that nurses in all the $\mathbf{4}$ central hospitals partially complied with assessment and planning standards. During assessment, the nurses assessed the physical aspects of care but did not assess the psychological, spiritual and cultural aspects of care. At planning the nurses assigned and delegated tasks based on the knowledge and skills of the provider selected but did not comply with factors related to safety, effectiveness and cost of care. All the facilities fully complied with implementation standard because they implemented care in a safe and appropriate manner and communicated with patients/ significant others and other health care providers. However, regarding systematic and ongoing evaluation of patients' condition only Mzuzu Central hospital partially complied while the rest of the facilities were not compliant. All the facilities did not comply with documentation standard of care because the patient records were not legible and did not precisely depict comprehensiveness of care nor bore signatures of the implementers of the care. Results are discussed by
\end{abstract}

"Corresponding author. relating the level of compliance to standards and the quality of patient care.

Keywords: Nursing Standards; Implementation Practices; Documentation Practices; Surgical Incision; Critical Patient Care

\section{INTRODUCTION}

"Nursing" or "practice of nursing" means caring, commitment and dedication to meeting the health needs of all people [1]. Nurses direct care to promote, maintain and restore health in various settings to individuals, families and communities. They are prepared to identify and assist with the health care of all populations [1]. Nursing practice is composed of a wide variety of roles and responsibilities necessary to meet the health care needs of society [2]. The State Registered Nurse Midwives (SRNMs) are expected to offer skilled care to those recuperating from illness or injury, advocate for patients' rights, teach patients so that they make informed decisions, support patients at critical times and help them navigate the increasingly complex health care system. Society views the quality of nursing practice based on the scope of practice. The unique focus of nursing is on the response of an individual or group to an actual or potential health problem or life process.

Every state registered nurse midwife, when entering the nursing profession, assumes the responsibility of public trust and its corresponding obligation to adhere to set standards of nursing practice. Nursing uses scientific knowledge and combines critical thinking skills with caring behaviour. The State Registered Nurse Midwife (SRNM) is responsible and accountable for the quality of nursing care given to clients. It is therefore expected of them to comply with the standards in the clinical nursing practice settings throughout the country. The standards set by the Nurses and Midwives Council of Malawi [3] 
cannot be separated from practice. The NMCM has structure, process, and outcome standards set for state registered nurse midwives in Malawi.

The Ministry of Health in Malawi started reforming the health sector in December, 1999, with emphasis on quality assurance, which is being addressed within the new health policy [4]. The overall objective of the policy is to improve the quality of care through service delivery, integration, capacity building and training of health care personnel to provide quality care. Malawi's Nurse Practice Act [5] under the NMCM protects the public by legally defining and describing the scope of nursing practice. Furthermore, the Act also legally controls nursing practice through licensing requirements to ensure compliance with standards of care. Nurses who know and follow their Nurse Practice Act and standards of care provide safe and competent nursing care [6]. In Malawi, literature on the compliance of registered nurse midwives to nursing standards is scanty, therefore the aim of this study was to describe the practice of SRNM's on postlaporatomy patients in public central hospitals in Malawi and compare them to the set process standards by the Nurses and Midwives Council of Malawi. Specifically, the study assessed the quality of professional practice and identified the extent of the care SRNM provided for patients and if they were in line with the set standard of care.

\section{METHODS}

\subsection{Design and Setting}

The study design was descriptive cross sectional and utilized quantitative data collection and analysis method to describe the quality of professional practice as reflected in clinical nursing care of patients. Four tertiary facilities (Central hospitals) which provide postlaparotomy services to patients in the country were selected. The facilities were, Kamuzu, Mzuzu, Queen Elizabeth and Zomba Central hospitals. The study was conducted for 6 days at each facility. Consenting adult male and female patients that were admitted in the surgical wards of the facilities after undergoing surgery due to laparotomy were recruited. A total of 100 patients were admitted during the time of the study and all consented to participate in the study. The patients' records from the day of arrival at the unit from theatre to day three in the ward were reviewed. The state registered nurse midwives that provided clinical nursing care to post-laparotomy patients were observed for compliance with set process standards in the care of the patients. A total of 48 SRNMs were available in the surgical wards during the time of the study and all consented to participate in the study. A checklist was used to collect the data. The checklist had five NMCM set standards on assessment, planning, implementation, evaluation and documentation of care. The marks against each nurse were categorized into a three-point rating scale; Noncompliance (C) $<0.5$ - 0.0; Partial compliance (C) $<1.0$ - 0.5; and Compliance $\mathrm{C}=(1.0)$.

\subsection{Data Collection}

Nurses were observed as they rendered care to postlaparotomy patients by a registered nurse midwife. She was assisted by 2 research assistants who had experience in caring for laparotomy patients. The research team worked with the nurses for a number of days so that they got used to them and to prevent Hawthorne effect during data collection. Observations on practice were initially done before the midwives were interviewed. Hawthorne effect refers to psychological response in which participants of research change their behavior because they know that they are being observed [7]. The observations were done when the nurses were taking reports, during doctor's rounds and during actual practice, such as patient assessment and briefing sessions when staff members were coming from the off days. Reactivity and observer biases were thus eliminated [8]. The research team reviewed the patient record according to the five NMCM set process standards of assessment, planning, implementation, evaluation and documentation. The patient records were collected after report taking and each data collector analyzed a separate patient record of post-laparotomy for day three in order to get a full picture of the care given.

\subsection{Ethical Consideration}

The study was approved by internal ethical review boards in Malawi (College of Medicine Research and Ethics Committee) and in South Africa (University of South Africa, Health Studies Research and Ethics Committee). Permission to collect data in the four facilities was obtained from the heads of the facilities. Informed consent was obtained from all the participants who were informed of the objectives of the study and were told that they were free to withdraw at anytime if they wished and that their decision to withdraw would not affect their treatment and care at the hospital. The study used codes to refer to patients to ensure participants' confidentiality and anonymity.

\subsection{Inclusion and Exclusion Criteria}

The study targeted SRNMs that were working in the surgical wards of public central hospitals in Malawi where clinical care to post laparotomy patients was provided. The study also targeted the records of all adult post laparotomy patients from the day of arriving in the 
ward after operation in the theatre, to the third day of stay in the ward. All other cadre of staff other than SRNMs or all other surgical patients other than post laparotomy were excluded from the study.

\subsection{Data Analysis}

Data was analyzed using SPSS version 16.0. Descriptive statistics were computed for the data. The results are presented as mean scores across the nurses on each of the 5 process standards; assessment, planning, implementation, documentation and evaluation. Means of 1.0 across a standard at a given facility signified compliance $(\mathrm{C}=1)$ while those of less than 1.0 to 0.5 signified partial compliance and means of less than 0.5 to 0.0 represented non compliance.

\section{RESULTS}

\subsection{Demographic Data}

The mean participants' ages were; 43 (range 33 - 67) years at Kamuzu Central hospital, 49 (range 42 - 66) years at Queen Elizabeth Central Hospital, 41 (range 28 73) years at Zomba Central Hospital and 45 (range 37 67) years. The demographic characteristics of the patients by facility are shown in Figure 1. Most of the patients (over 90\%) at each facility were employed. Across facilities, there were equal proportions of the males and females, the employed and unemployed (Figure 1).

The SRNM's that were working in the tertiary institutions were all females with the majority of them (92\% at Kamuzu, 94\% at Mzuzu, 95\% Queen Elizabeth and $98 \%$ at Zomba Central hospitals) being married. Their ages ranged from 23 to 56 years at Kamuzu, 35 to 67 years at Mzuzu, 24 to 55 years at Queen Elizabeth and 24 to 59 at Zomba Central hospitals. The nurses had varying working experience ranging from 5 to 15 years in the surgical wards.

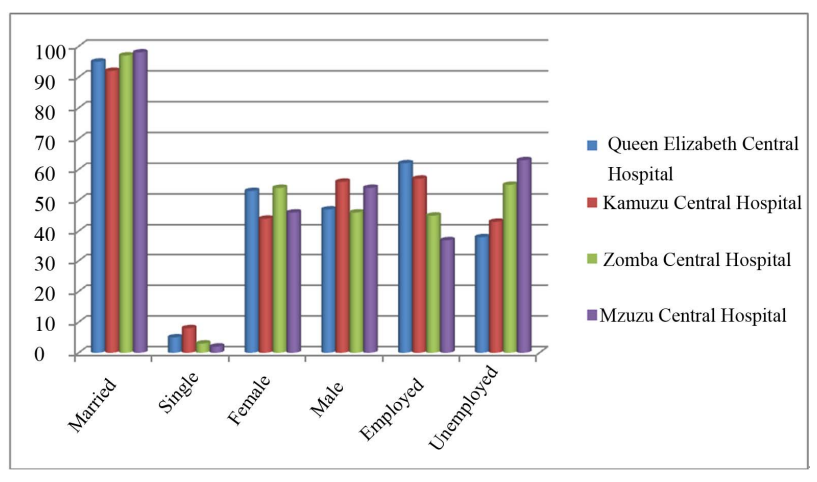

Figure 1. Demographic characteristics of laparotomy patients at Kamuzu Central Hospital, Mzuzu Central Hospital, Queen Elizabeth Central Hospital, and Zomba Central Hospital.

\subsection{Evidence of Compliance to NMCM Set Process Standards}

Scores for each facility across the 5 standards are shown in Table 1.

All the 4 central hospitals partially complied with assessment and planning standards (Table 1). Regarding the assessment standard, the nurses assessed the physical aspects of care but they did not assess the psychological, spiritual and cultural aspects of care. During planning, all the nurses assigned and delegated tasks based on the knowledge and skills of the provider selected. They however, did not comply with factors related to safety, effectiveness and cost of care, hence partial compliance.

Results show that all the facilities fully complied with implementation standard. The facilities implemented care in a safe and appropriate manner with evident communication with patients/significant others and other health care providers. Regarding systematic and ongoing evaluation of patients' condition only Mzuzu Central hospital partially complied with the evaluation standard while the rest of the facilities were not compliant (Table 1). At Mzuzu, the nurses evaluated effectiveness of care in relation to outcome. In all the facilities, the nurses did not make diagnosis based on assessment data and did not assess personal data for complete patient history.

All the facilities did not comply with documentation standard of care. Results from patient record analysis show that the nurses did not make sure that the records were legible and that they precisely depicted comprehensiveness. The records in addition did not bear signatures of the implementers of the care.

\section{DISCUSSION}

The SRNMs partially complied with the assessment standard. According to the Nurses and Midwives Council Standards [3], the nurses were supposed to assess the patients in terms of their physical, spiritual, psycho-

Table 1. Scores of State Registered Nurse Midwives across the five Nurses and Midwives' Council of Malawi Standards during their practice at 4 tertiary facilities in Malawi.

\begin{tabular}{ccccc}
\hline & \multicolumn{4}{c}{ Scores for Each Tertiary Health Facility } \\
\cline { 2 - 5 } Standards of Care & $\begin{array}{c}\text { Kamuzu } \\
\text { Central } \\
\text { Hospital }\end{array}$ & $\begin{array}{c}\text { Mzuzu } \\
\text { Central } \\
\text { Hospital }\end{array}$ & $\begin{array}{c}\text { Queen } \\
\text { Elizabeth } \\
\text { Central } \\
\text { Hospital }\end{array}$ & $\begin{array}{c}\text { Zomba } \\
\text { Central } \\
\text { Hospital }\end{array}$ \\
\hline Assessment & $0.9-0.5$ & $0.9-0.5$ & $0.9-0.5$ & $0.9-0.5$ \\
Planning & $0.9-0.5$ & $0.9-0.5$ & $0.9-0.5$ & $0.9-0.5$ \\
Implementation & 1.0 & 1.0 & 1.0 & 1.0 \\
Evaluation & $0.4-0.3$ & $0.9-0.5$ & $0.4-0.3$ & $0.4-0.3$ \\
Documentation & $0.4-0.3$ & $0.4-0.3$ & $0.4-0.3$ & $0.4-0.3$ \\
\hline
\end{tabular}


logical, cultural and economic status in order to have a complete history of the patients. The complete history would in turn assist in the provision of comprehensive care to the patients. The nurses instead partially complied with the assessment standard because they concentrated only on the physical assessment of the patients. Results suggest that nurses in this study were following recommendations by Lewis et al. [2], that physical needs of patients should be addressed before the other needs. However, after assessing the physical needs, the nurses were supposed to assess the other needs so that they provide complete and holistic care to the patients. The imbalance between assessment of the physical needs and other aspects including the psychological needs of patients may have compromised the quality of postlaparotomy care in this study. For example some patients may have presented with mental problems which needed intervention or beliefs which would make them to refuse certain treatment such as blood transfusion. Patient assessment according to the standard could have revealed these other needs of the patients and appropriate intervention or care rendered.

Work overload of the nurses in the surgical wards of the facilities in this study could have contributed to the fact that the nurses concentrated on the physical assessment only. The wards had on average 70 patients against one SRNM (Nurse: patient ratio of 1:70). This ratio is seven times higher than the recommended ratio of 1:10 [3]. Despite the high nurse patient ratio, the nurses could still have complied with the patient assessment standard by prioritizing the patients according to their state of condition. It is therefore recommended that patients are fully assessed so that comprehensive care is provided.

Results show partial compliance with planning standard in all facilities because the nurses did not comply with factors related to safety, effectiveness and cost of care. Compliance with the planning standard would ensure proper utilization of the available resources and that clients' and or significant others are properly assisted. Compliance with planning standard could also assist in identifying and utilizing appropriate services that are available to address health related issues. Similar results of partial compliance with planning standard are reported by a number of authors $[9,10]$. These authors have attributed shortage of staff as a contributing factor for partial compliance with the planning standard. However, in this study both the material and human resources were inadequate and therefore contributed to partial compliance with the planning standard. The partial compliance with planning standard adversely affected quality of care. For example, some patients' wounds were infected and some patients did not receive their medication at the prescribed time. Some patients that needed pain killers were not given immediately the drugs were ordered. It is therefore recommended that nurses comply with planning standard so that comprehensive care is rendered to post-laparotomy patients.

The nurses fully complied with implementation process. Results show that the nurses implemented care in a safe and appropriate manner and they maintained communication with patients, significant others and other health care providers. Results show that the SRNM were competent in carrying out implementation procedures required in the nursing practice. This may be related to the way that they are trained and their experience in working with patients in the wards as most of them had cared for post-laparotomy patients for more than 5 years. Similar results are reported by Karkkainen and Eriksson [11].

The nurses in this study did not fully comply with evaluation standard. They partly complied with evaluation standard because they concentrated on other aspect of care. The results are similar with a study conducted by Karkainen and Eriksson [11] which show recommended improvements in patient teaching and recording of patients' own opinion. The partial compliance with evaluation standard had negative implications on the quality of care. The nurses were supposed to evaluate their process of care with full involvement of the client, family members and other health members. The evaluation would assist them to determine the effectiveness of interventions in relation to outcomes and to revise diagnosis, outcomes and plan of care as needed. Evaluation could also have assisted the nurses to check if any treatment implemented had an effect on the patient's condition. It is therefore recommended that evaluation standard be fully complied with so that the effectiveness of post-laparotomy care is determined.

The results for documentation show that all facilities did not comply because the clients' records were not legible, did not depict comprehensiveness and did not bear the signatures of the implementers of care. Instead, the nurses concentrated on implementing the aspects of care but without keeping any records. Similar results were reported by Rodden and Bell [12] in their study in the United Kingdom in which documentation was described as a forgotten skill by practicing nurses. These results are reported despite the fact that documentation is a legal requirement [13]. Documentation allows hospital staff to share information about patients. Information sharing can help reduce duplication thereby reducing the amount of workload for the already few available nurses and time spent on diagnosing illnesses that have already been previously identified by other health workers. It also protects hospital staff against unforeseeable legal claims. This is more important now that documentation standard is complied with in view of the increased number of lawsuits in which patients sue health workers. In addition, 
patient complaints have increased considerably over the past few years thus making documentation vital for future reference. The time spent by SRNM in answering law suits and patient complaints is worth any time savings that might have initially been made when the SRNM properly follow the nursing process. In most cases, hospital documents have to be kept for a specified period before they are destroyed. It is therefore essential that nurses comply with the documentation standard so that comprehensive care to clients is well documented for future reference.

\section{CONCLUSION}

The nurses complied with implementation standard because they perceived it to be the main thrust of their profession. However, they partially complied with assessment and planning standard and did not fully comply with evaluation and documentation. Thus the quality of care in the facilities was compromised. To raise the quality of care according to stipulated standard, it is recommended that the nursing standards be strictly enforced in Malawi to ensure the quality of care. In addition, the number of SRNMs should be increased through increased student intake and retention of the current workforce through incentives. There is also a need to introduce in service training on nursing standards and the current nursing curriculum needs to be reviewed to incorporate issues of compliance to nursing standards.

\section{LIMITATION}

The study was limited to post-laparotomy patients in public central hospitals in Malawi. Therefore, the results may not be generalized to other settings. However, the results paint a general picture about Nurses compliance with NMCM standards of care.

\section{ACKNOWLEDGEMENTS}

The study was conducted as part of the senior author's Master of Arts degree in Health Studies at University of South Africa, with funding from University of Malawi, Kamuzu College of Nursing.

\section{REFERENCES}

[1] Craven, R.F. and Hirnle, C.J. (2013) Fundamentals of nursing, human health and function. 7th Edition, Wolters Kluwer, Lippincott and Williams and Wilkins, Philadelphia.
[2] Lewis, S.L., Heikemper, M.M., Dirksen, S.R., O’Brien, P.G. and Bucher, L. (2007) Medical-surgical nursing: Assessment and management of clinical problems. 7th Edition. Mosby Elsevier, St Louis.

[3] Nurses and Midwives Council of Malawi (2005) A regulatory body committed to the promotion and upholding of professional standards and protection of public health. Government Printers, Zomba.

[4] Ministry of Health and Population (1999-2004) National health plan. Malawi Government Press, Lilongwe.

[5] Nurses and Midwives Council of Malawi (1995) Nurses and midwives act (act 16 of 1995). Government Printers, Zomba.

[6] Kozier, B., Erb, G. and Blais, K. (2004) Professional nursing practice: Concepts and perspectives. 7th Edition, New Jersey, Pearson Education, 265p.

[7] Rayner, A., McLachlan, H., Forster, D., Peters L. and Yelland, J. (2010) A statewide review of postnatal care in private hospitals in Victoria, Australia. BMC Pregnancy and Childbirth, 10, 26. doi:10.1186/1471-2393-10-26

[8] Polit, D.F and Beck, C.T. (2008) Nursing research: Appraising evidence for nursing practice. 7th Edition, Wolters Kluwer, Lippincott and Williams and Wilkins, Philadelphia, 566p.

[9] Kovner, C. and Gergen, J. (1998) Nurse staffing levels and adverse events following surgery in US hospitals. Image: The Journal of Nursing Scholarship, 30, 315-321. doi:10.1111/j.1547-5069.1998.tb01326.x

[10] Hall, L., Doran, D. and Pink, G. (2004) The relationship between nurse staffing models and patient outcomes. http://www.ncbi.nlm.nih.gov/guide/literature/

[11] Tzeng, H. and Ketefian, S. (2003) Demands for nursing competencies: An exploratory study in Taiwan's hospital system. Journal of Clinical Nursing, 12, 509-518. doi:10.1046/j.1365-2702.2003.00738.x

[12] Rodden, C. and Bell, M. (2002) Record keeping: Developing good practice. Nursing Standard, 17, 40-42. www.ncbi.nlm.nih.gov/pubmed/12360739

[13] Trenoweth, M.C. (2007) Succeeding in nursing and midwifery education. John Wiley \& Sons, West Sussex. 